\title{
The Effectiveness of Conservative Management for Parapharyngeal Abscess and Cranial Bones Osteomyelitis
}

\author{
Muhammad Rizwan Aziz ${ }^{1 *}$, Paula Chattington ${ }^{2}$, Faisal Saleem Khan ${ }^{3}$, Sohail Zahoor ${ }^{4}$ and \\ Haseeb Sadaqat ${ }^{5}$ \\ ${ }^{1}$ Warrington General Hospital Warrington, Speciality doctor in internal medicine WHH NHS Trust, United Kingdom \\ ${ }^{2}$ Consultant Endocrinologist Warrington General Hospital, United Kingdom \\ ${ }^{3}$ Consultant Physician \& Clinical Lead Internal medicine WHH NHS Trust \\ ${ }^{4}$ Consultant Physician Warrington General Hospital, United Kingdom \\ ${ }^{5}$ Clinical Fellow Warrington Hospital, United Kingdom \\ *Corresponding author: Muhammad Rizwan Aziz, Warrington General Hospital Warrington, Speciality doctor in internal medicine \\ WHH NHS Trust, United Kingdom
}

\section{ARTICLE INFO}

Received: 㹃 November 23, 2021

Published: 幽 November 29, 2021

Citation: Muhammad Rizwan Aziz, Paula Chattington, Faisal Saleem Khan, Sohail Zahoor, Haseeb Sadaqat. The Effectiveness of Conservative Management for Parapharyngeal Abscess and Cranial Bones Osteomyelitis. Biomed J Sci \& Tech Res 40(2)-2021. BJSTR. MS.ID.006425.

\section{ABSTRACT}

85 years old man admitted with a fall and head injury. Initially treated for head injury and sepsis for unknown source. CT scan head reported as age related changes. Later on noted to have right ear discharge Further CT scan head and neck showed large parapharyngeal abscess and Internal Jugular Vein (IJV) thrombus. Successfully managed with intravenous antibiotics and Low Molecular Weight Heparin (LMWH). Discharged home with community intravenous therapy and followed up in the ENT clinic.

Objective

Conservative management for parapharyngeal abscess in elderly people with special focus on the conservative management considering increased age and ongoing COVID 19 Pandemic.

Keywords: Abscess; Parapharyngeal; IJV; LMWH; CN

Abbreviations: IJV: Internal Jugular Vein; LMWH: Low Molecular Weight Heparin; ED: Emergency Department

\section{Introduction}

A parapharyngeal abscess is a deep neck abscess [1]. The parapharyngeal space is lateral to the superior pharyngeal constrictor and medial to the pterygoid muscle, it is divided into anterior and posterior compartments and contains many important structures [2]: carotid artery, IJV, CN V, IX, XI and XII. Abscesses in this area can present as fever, sore throat, difficulty in swallowing and neck swelling and rarely trismus. The diagnosis is based on history and clinical suspicion with evidence of a generalized neck infection. Confirmation is made with a CT scan head and neck with contrast. Management includes broad spectrum antibiotics [3] that have good blood brain barrier penetration and surgical intervention in complex cases. Major complications include airway compromise, severe sepsis, seizures, neurological deficit, carotid artery rupture, IJV thrombosis with septicaemia [4].

\section{Case Report}

85 years old male presented to Emergency Department (ED). He had a past medical history of epilepsy, chronic otitis media, 
ischaemic heart disease and hypertension. He was usually mobile and independent at home. He was found on the floor by his son with evidence of a head injury and bleeding. In the ED his CT head was reported as no acute intracranial abnormality. Blood tests showed inflammatory markers were raised; CRP 300, WBC 16, ESR 95 and he treated with broad spectrum antibiotics and superficial laceration was sutured. No obvious source of infection localised on the CT scan of his thorax, abdomen and pelvis. After 1 day stay on the acute medical unit he was transferred to the Care of Elderly ward where he had 2 episodes of seizures, self-terminated with good recovery [5]. His GCS remained 15 during course of admission and no acute neurological deficit on clinical examination. Later on noted to have a right ear yellow discharge, urgent ENT referral made and was seen by the ENT team. After initial assessment by the ENT team CT scan head and neck with IV contrast which showed a complex right parapharyngeal abscess with soft tissue inflammation in the right carotid space with, petrous and squamous bone destruction and right IJV thrombosis extending to the dural venous sinuses. He underwent series of CT head and neck scans and was listed for potential emergency surgical intervention by the ENT team. He was started on ceftriaxone and metronidazole for the abscess and LMWH for right IJV thrombus. Daily bloods showed improvement in CRP and ESR. Detailed discussions with ENT and microbiology teams and agreed for long term antibiotics through PICC Line. Repeat CT scan showed a reduction in the size of the abscess with no further bone destruction and stable IJV thrombus.

\section{Discussion}

Parapharyngeal abscesses are deep neck abscesses in the parapharyngeal space.

\section{Age}

Can develop in any age group, more common in children.

\section{Potential Causes (5)}

a) Acute and chronic tonsillitis

b) Chronic otitis media

c) Peritonsillar abscess

d) Dental infections

e) Extension of existing deep neck abscesses like retropharyngeal or submandibular

f) Traumatic

g) Iatrogenic post-operative or local anesthetics

\section{Clinical Presentation}
a) Fever
b) Sore throat

c) Dysphonia

d) Pain

e) Neck swelling,

f) Dysphagia

g) Dyspnoea

h) Stridor

\section{Examination Findings}

a) Tender neck

b) Erythema

c) $\mathrm{CN}$ findings

d) High grade fever

e) Malodourous

\section{Diagnosis}

Based on clinical suspicion arrange for CT scan - ideally CT scan $\mathrm{H} \& \mathrm{~N}$ with contrast.

\section{Treatment}

Don't delay treatment

a) Broad spectrum antibiotics

b) Blood cultures / swabs

c) Early call to specialist team

d) Low threshold for l surgical intervention

\section{Complications}

a) Airway compromise

b) Extension to neighbouring structures (IJV thrombosis)

c) Meningitis

d) Seizures

e) Extension into carotid artery with subsequent mycotic aneurysm

f) Spread to mediastinum

g) Local bleeding

h) $\mathrm{CN}$ involvement.

\section{References}

1. Cuete, David (2017) Radiology Reference Article: Parapharyngeal abscess. Radiopaedia.org.

2. Sasaki, Clarence T (2016) Ear, Nose, and Throat Disorders: Parapharyngeal Abscess. MSD Manual Professional Edition. Merck Sharp \& Dohme Corp. 
3. Croche Santander B, Prieto Del Prado A, Madrid Castillo MD, O Neth, Obando Santaella (2011) Retropharyngeal and parapharyngeal abscess: experience in a tertiary-care center in Seville during the last decade. An Pediatr 75(4): 266-272.

4. Alaani A, Griffiths H, Minhas SS (2005) Parapharyngeal abscess: diagnosis, complications and management in adults. Eur Arch Otorhinolaryngol 262(4): 345-350.

ISSN: 2574-1241

DOI: $10.26717 /$ BJSTR.2021.40.006425

Muhammad Rizwan Aziz. Biomed J Sci \& Tech Res

(C) (P) This work is licensed under Creative

Submission Link: https://biomedres.us/submit-manuscript.php
5. Dhingra PL (2014) Diseases of Ear, Nose and Throat \& Head and Neck Surgeries ( $6^{\text {th }}$ Edn.)., In: Dhingra PL (Edt.)., Elsevier, Netherlands.

$\begin{array}{ll}\text { BIOMEDICAL } & \text { Assets of Publishing with us } \\ \text { RESEARCHES } & \text { - Global archiving of articles } \\ & \text { - Immediate, unrestricted online access } \\ & \text { - Rigorous Peer Review Process } \\ & \text { - Authors Retain Copyrights }\end{array}$

